\title{
Thermal Fatigue Analysis of Hot Forging Closed Dies ${ }^{1}$
}

\author{
Pedro Ivo Vianello ${ }^{a^{*}}$ (1) , Anderson Junior dos Santos ${ }^{a}$, Alexandre Mendes Abrão ${ }^{b}$, \\ Frederico de Castro Magalhães ${ }^{b}$

\begin{abstract}
${ }^{a}$ Universidade Federal de Minas Gerais, Programa de Pós-Graduação em Engenharia Mecânica, Av. Antonio Carlos, 6627, Pampulha, CEP: 31270-901, Belo Horizonte, MG, Brasil.

${ }^{b}$ Universidade Federal de Minas Gerais, Departamento de Engenharia Mecânica, Av. Antonio Carlos, 6627, Pampulha, CEP: 31270-901, Belo Horizonte, MG, Brasil.
\end{abstract}

Received: December 30, 2019; Revised: April 16, 2020; Accepted: June 12, 2020

\begin{abstract}
The aim of this work is to develop a numerical subroutine for the commercial finite element method software QFORM VX 8.1.4 capable of predicting, simultaneously, regions of closed dies which are prone to thermal fatigue as well as the number of cycles required for thermal fatigue cracking. The numerical subroutine was based on Manson (thermal fatigue) and Coffin-Manson (number of cycles) equations. Hot forging of AISI 1045 grinding balls using AISI H13 closed dies was performed and the numerical and experimental results were compared. The findings indicated that after forging 66 grinding balls, the numerical model achieved steady state for the temperature inside the die. After forging 600 grinding balls, both the experimental and numerical results showed that the regions of the dies subjected to the highest thermal gradient were prone to thermal fatigue. In addition to that, the numerically predicted values for the onset of thermal cracking were consistent with the experimental results: 517 and 600 cycles, respectively.
\end{abstract}

Keywords: Hot Forging, thermal fatigue, finite element method, AISI H13 steel.

\section{Introduction}

The metallurgical sector has a significant importance to the global economy, with vast segments of the productive chain connected to metallurgy, machining and manufacturing. Therefore, the metallurgical sector can be considered the basis of other relevant activities, such as the automotive and civil engineering ${ }^{1}$. The global metal forging market was estimated in USD 78.60 billion in 2018 and a growth of $7.6 \%$ is expected between 2019 to $2025^{2}$. With regard to Brazil, 16 million tons are produced by this sector, of which 146,000 tons are forged products. The production of forged component with high surface and dimensional quality at low cost requires that all steps involved (cutting, heating, forging, trimming, etc.) be constantly monitored. Among these production steps, forging itself is the most costly, since dies can represent 10 to $30 \%$ of the total cost of a forged part or mechanical component ${ }^{3}$.

The service life of hot forging closed dies can be expressed by the number of parts produced before rejection and, in general, rejection results from some type of failure that may modify the dimensions and/or geometry of the final forged product or may lead to failure of the closed dies $^{4}$. The prediction of the service life of hot forging dies is a significant challenge to forging companies. The failure mechanisms presented in hot forging closed dies include abrasion wear, plastic strain, as well as mechanical fatigue

\footnotetext{
${ }^{1}$ This paper was presented in the $10^{\text {th }}$ Brazilian Congress on Manufacturing Engineering, August 2019, São Carlos/SP.

*e-mail: pivianello@yahoo.com.br
}

and thermal fatigue 5 . Figure 1 shows the typical failure mechanisms and corresponding locations in hot forging closed dies.

During the service life of hot forging closed dies, certain regions of the die previously heated to reach $250-300^{\circ} \mathrm{C}$ are further heated by the billet to be forged $\left(950-1200^{\circ} \mathrm{C}\right)$ and subsequently cooled with the application of release agents. This thermal cycle promotes thermal fatigue, which is characterized by cracks on the surface of the die and according to Becker and Shipley ${ }^{6}$, they usually start after a short period of less than $1 \%$ of the service life of the die, thus characterizing low cycle fatigue ( $<1,000$ cycles). The severity of the thermal cycle is mainly determined by the temperature gradient, the maximum temperature and the heating and cooling rates. Thermal cracks tend to develop in regions free of any stress concentrator. For low-cycle thermal fatigue, the amplitude of thermal strain must exceed the elastic limit of the material ${ }^{7}$, which can be expressed by Equation 1 .

$\alpha\left(T_{2}-T_{1}\right)>2 \frac{\left(1-v_{1}\right) \sigma_{1}}{E_{1}}+2 \frac{\left(1-v_{2}\right) \sigma_{2}}{E_{2}}$

Where $\alpha$ is the average coefficient of thermal expansion, $v_{1}$ and $v_{2}$ are the Poisson's coefficients, $\sigma_{1}$ and $\sigma_{2}$ are the stresses and $\mathrm{E}_{1}$ and $\mathrm{E}_{2}$ are the modulus of elasticity for the minimum $\left(\mathrm{T}_{1}\right)$ and maximum $\left(\mathrm{T}_{2}\right)$ temperatures, respectively. According to Coffin and Manson ${ }^{8}$, the number of cycles for the onset of low-cycle thermal cracks can be determined by Equation 2 . 


$$
\mathrm{N}_{\mathrm{f}}=\left[\frac{\mathrm{C} \cdot \varepsilon_{\mathrm{f} 1}}{\alpha\left(\mathrm{T}_{2}-\mathrm{T}_{1}\right)-\frac{\left(1-\mathrm{v}_{1}\right) \sigma_{1}}{\mathrm{E}_{1}}-\frac{\left(1-\mathrm{v}_{2}\right) \sigma_{2}}{\mathrm{E}_{2}}}\right]^{1 / \mathrm{n}}
$$

Where $\mathrm{N}_{\mathrm{f}}$ is the number of cycles to initiate thermal cracking, $\varepsilon_{\mathrm{fl}}$ is the true strain for the fracture, $\mathrm{n}$ and $\mathrm{C}$ are constants ranging from 0 to 1 . Equations 1 and 2 depend on the mechanical properties and local temperatures in forging dies.

There are few experimental and numerical studies aiming at both identifying the regions susceptible to thermal fatigue and determining the number of cycles for their initiation in hot forging closed dies, particularly for specific applications, such as AISI H13 hot work die steel. This paper aims to complement the studies by Magalhães et al. ${ }^{9}$ in which a numerical subroutine was developed to determine the number of cycles required to initiate thermal cracks in regions prone to low-cycle thermal fatigue. The numerical study employed Qform VX 8.1.4 commercial software (Quantor, Moscow, Russia), however, it is noteworthy that this code does not report the number of cycles to failure or the regions prone to thermal fatigue as outputs. For this purpose, a subroutine was written in LUA programming and used the data provided by Qform as input. The numerical results obtained via finite element method were compared with experimental data in order to validate the proposed numerical subroutine.

\section{Materials and Methods}

A computational subroutine based on Equations 1 and 2 was developed using LUA programming language and implemented in QForm VX 8.1.4 software for the numerical prediction of the regions prone to thermal fatigue and the number of cycles required for crack initiation in closed dies used to forge grinding balls. Subsequently, the numerical results were compared with experimental data.

\subsection{Materials}

Closed dies (Figure 2a) were used to hot forge grinding balls (Figure 2b) with a nominal diameter of $90 \mathrm{~mm}$ and dimensional tolerance of $\pm 2 \mathrm{~mm}$. The closed dies were made of AISI H13 steel with an average hardness of $550 \mathrm{HV}$ obtained after quenching and tempering. As work material, AISI 1045 steel cylindrical bars with a nominal diameter of $76.2 \mathrm{~mm}$ were used. In order to prevent buckling during forging, Grünning ${ }^{10}$ recommends that the billet height do

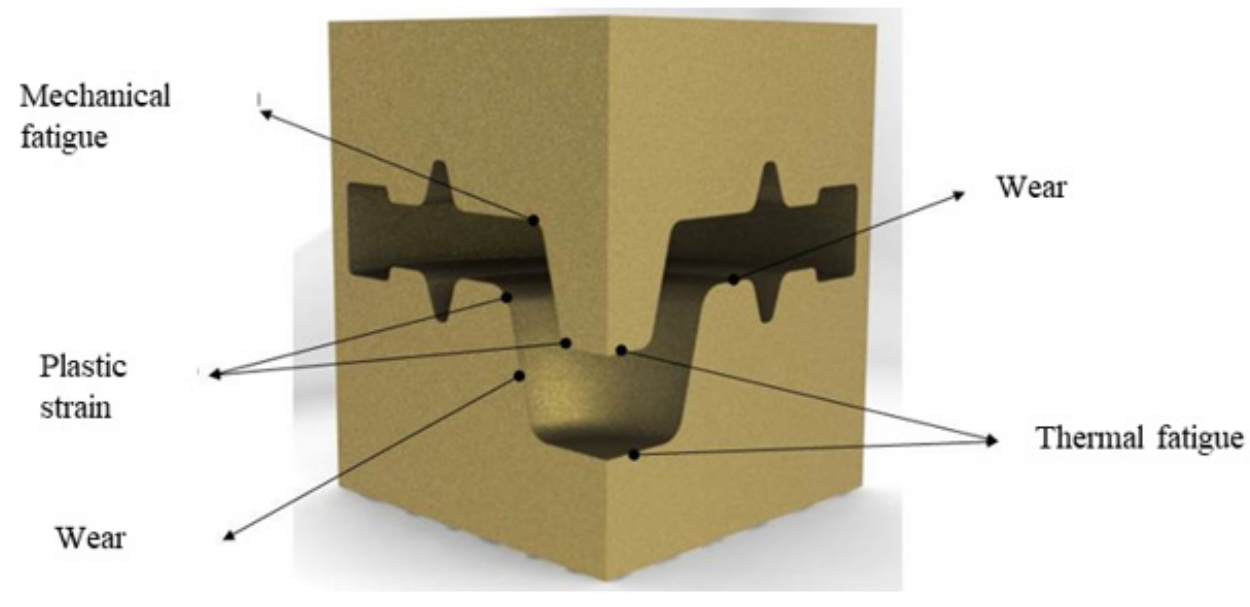

Figure 1. Typical failure mechanisms in hot forging closed dies.
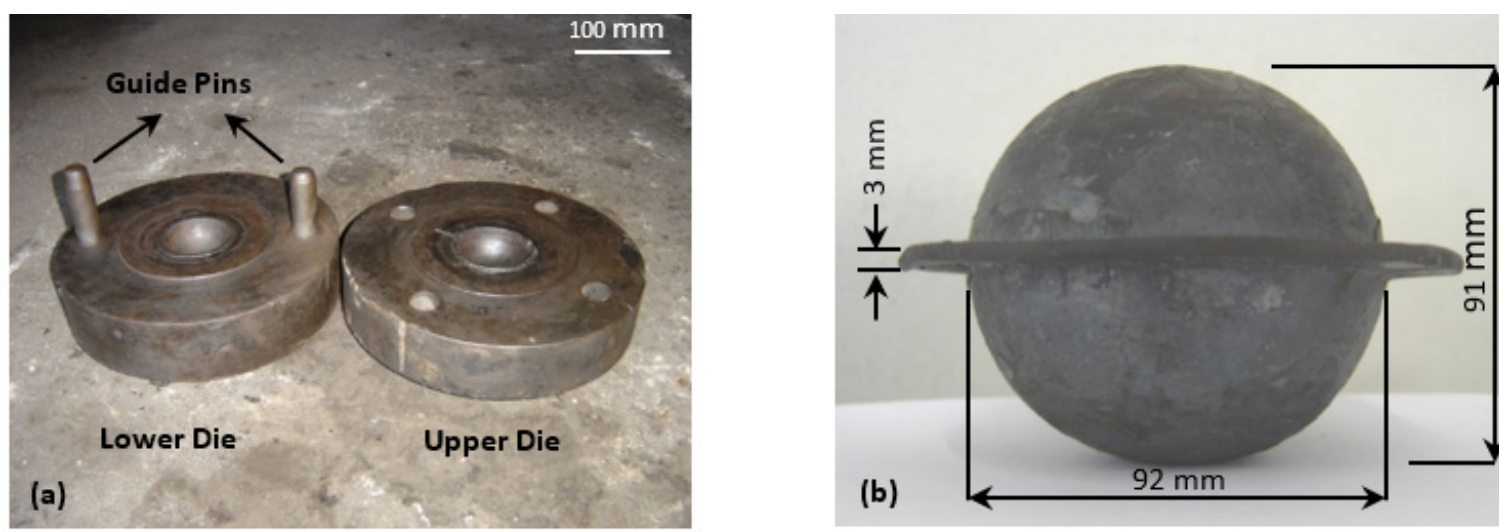

Figure 2. (a) Hot forging closed dies and (b) forged grinding ball with flash. 
not exceed 2.5 times its diameter, thus a height of $120 \mathrm{~mm}$ was selected. When heated in a fuel oil furnace, a mass loss of approximately $1 \%$ is observed in the billet due to oxide formation $^{11}$ and for this reason the billets were heated in an induction furnace to reach the temperature of $950{ }^{\circ} \mathrm{C}^{12}$.

Each billet was placed in the upright position supported by the lower die, which was preheated to $250^{\circ} \mathrm{C}$ together with the upper $\mathrm{die}^{12}$. Preheating was performed to avoid thermal shock, moreover, this temperature is recommended for hot forging of AISI 1045 medium carbon steel. Heating of dies was undertaken using gas heaters and a type $\mathrm{K}$ thermocouple was used to measure the temperature of the billet, dies and at the points to be studied in the cavity of the lower die. The total time for forging one grinding ball was 20 seconds considering billet transport to the friction press, positioning the billet on the lower die, forging, removal of the forged product and the application of the release agent ( $4 \%$ graphite in water) in the dies. It is noteworthy that the release agent was applied after forging each grinding ball.

\subsection{Finite element method}

QForm VX 8.1.4 software was employed for finite element modeling and simulation of hot forging using the explicit formulation in which the acceleration values must be calculated at each instant of the integration time. In order to reduce the computational time, the dies and billet had the same axis of revolution, thus the numerical simulations were reduced to the bidimensional axisymmetric condition (Figure 3).

The billet was modeled as an isotropic and elastoplastic material and was initially discretized with 5,760 triangular elements of second order. During the forging process, the

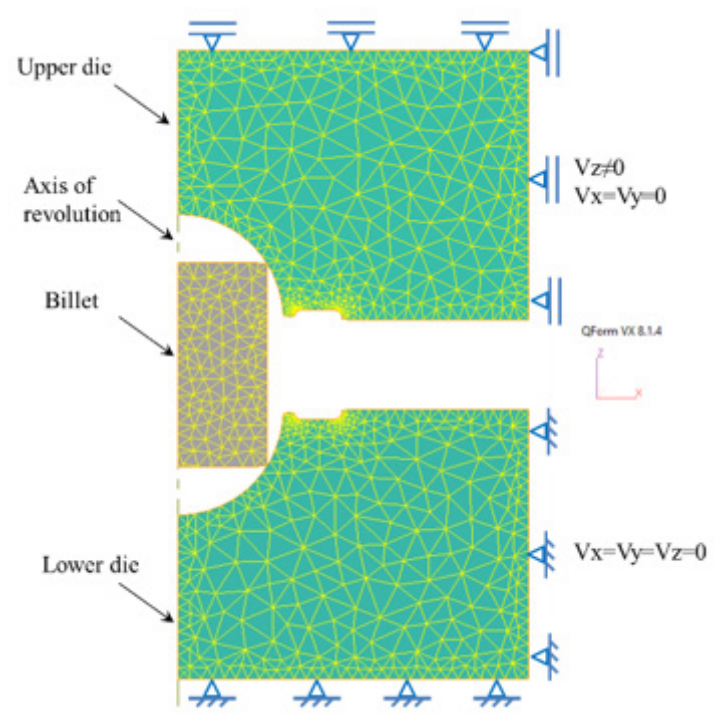

Figure 3. Forging process model. elements subjected to high plastic strain, especially in the flash gutter, were automatically remeshed to ensure better discretization of the newly deformed billet geometry. At the end of the process the forged grinding ball was discretized with 7,182 triangular elements. The flow curves used to describe the behavior of AISI 1045 steel during the forging cycles were a function of strain, strain rate and temperature and their mechanical and thermal properties were obtained directly from the library of QForm VX 8.1.4 software. In order to predict the regions prone to thermal fatigue and the number of cycles for crack initiation, the lower and upper dies were modeled as isotropic and elastic materials. Similarly, the mechanical properties of the dies were taken from the library of QForm VX 8.1.4 software. To discretize the dies, the same number of triangular elements of second order was used $(26,178)$ and since they behaved elastically and were not automatically remeshed, a satisfactory convergence was obtained in the results concerned with thermal fatigue. The Levanov hybrid model was assumed to represent the friction at the interface between dies and billet after the application of the release agent and a coefficient of friction of 0.4 was used, as reported by Semiatin ${ }^{13}$.

\subsection{Thermal parameters and heat transfer conditions}

During forging billet and dies are subjected to heating caused by plastic strain of the billet, friction at the billet/ dies interfaces and heat dissipation through convection to the environment. In numerical simulation, one estimates that $95 \%$ of the plastic strain is converted to heat. This value can be adjusted in the software QForm VX 8.1.4 and was based on the study by Chun ${ }^{14}$.

The room temperature of the release agent temperature was assumed to be $25{ }^{\circ} \mathrm{C}$ and the thermal properties of the billet and dies were obtained from the library of QForm VX 8.1.4 software. The following coefficients for heat transfer were employed: dies/billet: $15 \mathrm{~kW} / \mathrm{m}^{2} . \mathrm{K}$, lower die/upper die: $10 \mathrm{~kW} / \mathrm{m}^{2} . \mathrm{K}$, application of release agent (cooling): $10 \mathrm{~kW} / \mathrm{m}^{2} . \mathrm{K}$ and surface in contact with release agent: $30 \mathrm{~kW} / \mathrm{m}^{2} . \mathrm{K}$.

\subsection{Subroutine}

For the implementation of the numerical subroutine written in the LUA language, several forging cycles were simulated until thermal steady state was achieved in the lower die. This condition was obtained after forging 66 grinding balls ${ }^{9}$. It is noteworthy that in order to obtain this state, the thermal conditions of the previous cycle were transferred to the subsequent forging cycle. For the application of Equations 1 and 2 the following values were assigned to the variables: $\alpha=13 \times 10^{-6}{ }^{\circ} \mathrm{C}^{-1} ; \mathrm{v}_{1}$ e $v_{2}=0.3 ; \mathrm{E}_{1}$ e $\mathrm{E}_{2}=180 \mathrm{GN} \mathrm{m}^{-2}$; $\mathrm{n}=0.5 ; \mathrm{C}=0.1$ e $\varepsilon_{\mathrm{f} 1}=0.69$. These values were obtained from Maim and Norstrom ${ }^{15}$. 

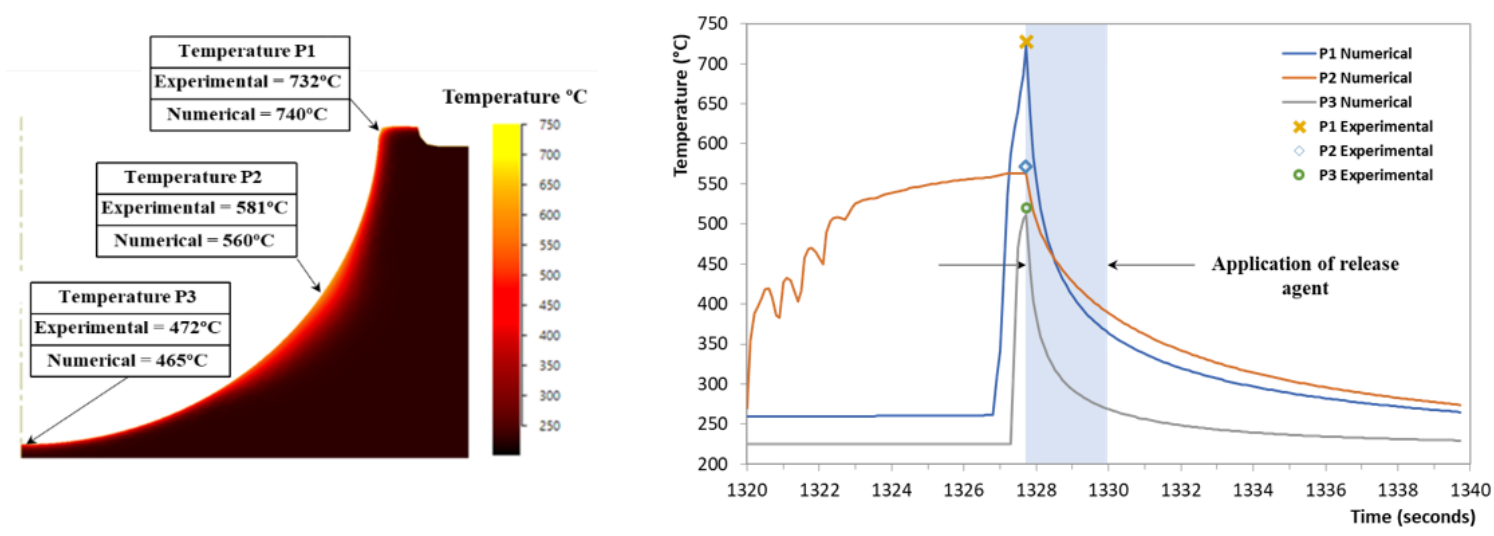

Figure 4. (a) Temperature distribution in the lower die at the end of forging and (b) numerical and experimental temperatures evolution at different positions.

\section{Results}

Considering that the steady state temperature in the dies was reached after forging 66 grinding balls, Figure 4a represents the numerical result for the temperature distribution in the internal cavity of the lower die after forging the $67^{\text {th }}$ grinding ball. In order to draw comparisons with the measured temperatures, three points were chosen: P1 (near the flash land); P2 (first point of contact between the billet and lower die) and P3 (lowest point of the cavity). The graph shown in Figure $4 \mathrm{~b}$ represents the temperature evolution during each forging cycle (positioning the billet in the lower die, forging, removal of the forged grinding ball and application of the release agent).

Highest temperatures at points P1 and P3 $\left(740{ }^{\circ} \mathrm{C}\right.$ and $465^{\circ} \mathrm{C}$, respectively) were obtained numerically when flash formation started (end of forging) and the dies were filled. The high temperature observed at point P1 may be responsible for another failure mechanism, namely plastic strain, which is associated with the reduction of the yield stress of the die. In contrast, at point P2, were the billet is held in lower die, the temperature increased gradually from $250^{\circ} \mathrm{C}$ to reach $610^{\circ} \mathrm{C}$ at the end of forging. After removal of the forged ball and application of the release agent both experimental and numerical temperatures stabilized at $280^{\circ} \mathrm{C}$ in points $\mathrm{P} 1$ and $\mathrm{P} 2$ and $255^{\circ} \mathrm{C}$ in point $\mathrm{P} 3$. Similar thermal behavior in the lower die was reported by $\mathrm{Chun}^{14}$. After obtaining the steady state for the maximum and minimum temperatures, the numerical subroutine was run and the regions subjected to highest thermal amplitudes were identified and considered suggestive of leading to thermal fatigue (green area in the lower die shown in Figure 5).

The numerical results predicted by the subroutine showed that the region near point P1 presented the lowest number of cycles (293 cycles) for the onset of thermal fatigue (cracks) followed, respectively, by the regions near points P2 (517 cycles) and P3 (1867 cycles), see Figure 6.

Experimentally, it was not possible to interrupt the process after forging the $293^{\text {th }}$ ball in order to search for evidence of thermal cracks near point $\mathrm{P} 2$, as predicted by the numerical subroutine. Thus, the lower die was inspected

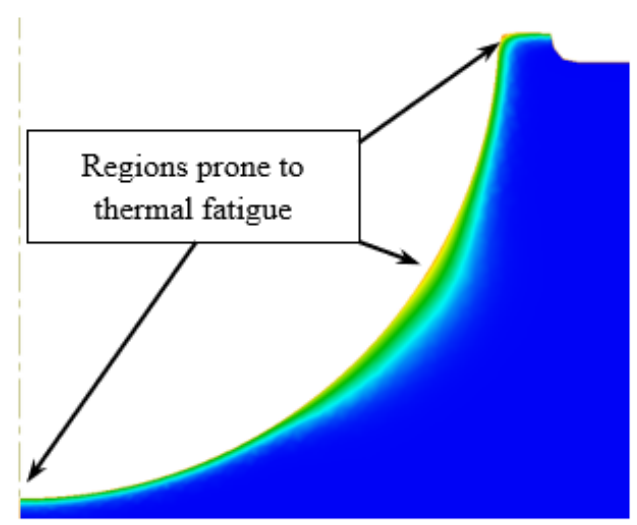

Figure 5. Regions in the lower die prone to thermal fatigue according to the numerical subroutine.

after 600 forging cycles because, according to numerical subroutine, the entire cavity of the lower die should have developed thermal cracks. Figure 7 shows the cavity of the lower die under two conditions: (a) before forging and (b) after forging 600 grinding balls.

After 600 cycles, homogeneous thermal cracks (resulting from thermal fatigue) are evident (orange peel aspect) in the entire cavity of the lower die, thus confirming the reliability of the proposed numerical subroutine. Additionally, two other failure mechanisms can be identified: plastic strain and mechanical cracks (mechanical fatigue) near the flash gutter. Figure 8 shows in detail these two failure mechanisms together with the thermal cracks. It is noteworthy that the combination of these failure mechanisms was observed by Sjöström and Bergström $^{16}$. The surface cracks, however, do not impair the dimensional tolerances of the forged parts, which in the present case (grinding balls) do not require further finishing. The lower die was recovered after forging 2500 balls due to plastic deformation near the flash gutter. 


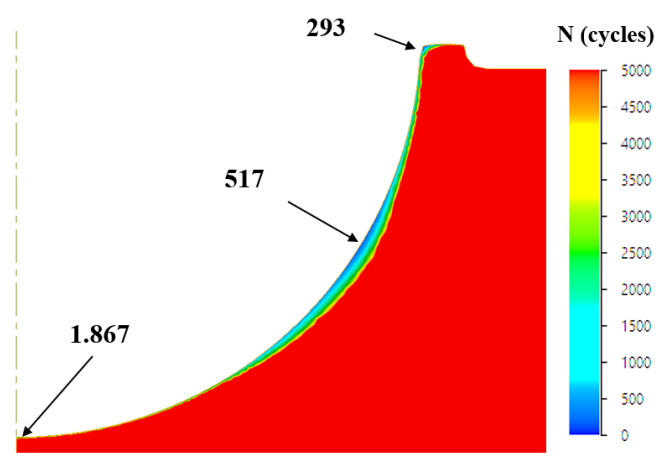

Figure 6. Prediction of the number of cycles for the onset of thermal fatigue.
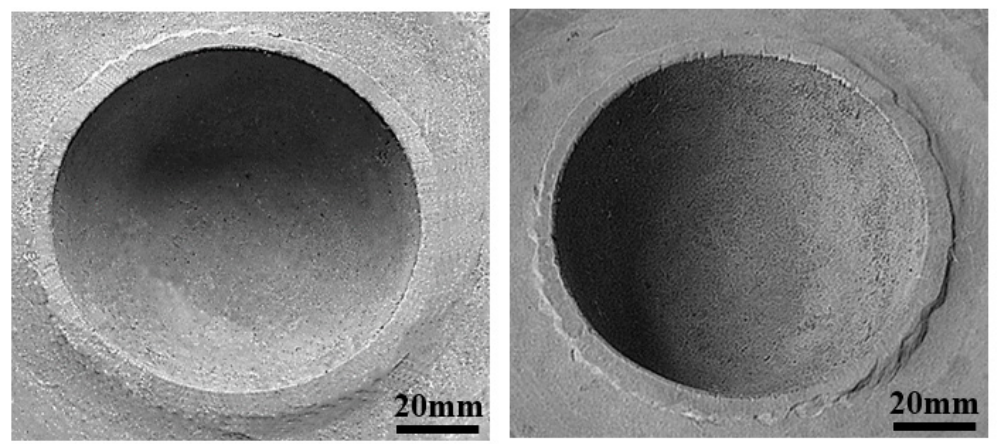

Figure 7. Lower die: (a) before forging and (b) after forging 600 balls.

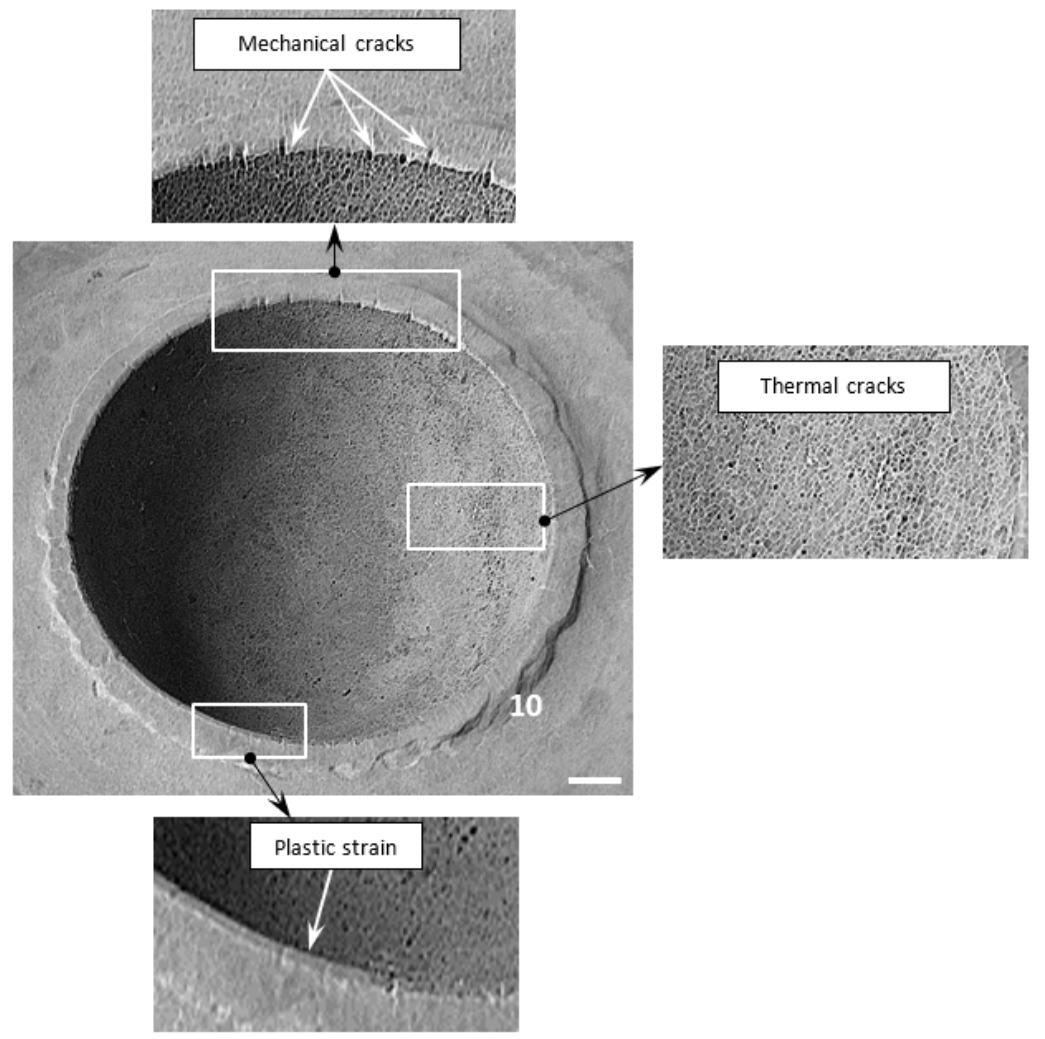

Figure 8. Top view of the cavity of lower die after 600 forging cycles. 


\section{Conclusions}

After conducting finite element modeling and simulation of hot forging of AISI 1045 steel grinding balls using AISI H13 closed dies and comparing the results with experimental data, the following conclusions can be drawn:

- $\quad$ After forging 66 grinding balls, Qform VX 8.1.4 software was able to accurately determine the steady state temperature in the lower die. Among the three measurement points, the largest relative error (3.61\%) was noticed at the first point of contact between the billet and lower die (simulated temperature of $560{ }^{\circ} \mathrm{C}$ and experimental temperature of $581{ }^{\circ} \mathrm{C}$ ).

- The proposed subroutine was able to predict the regions of the lower die where thermal fatigue occurred during the experimental work.

- In addition to presenting the highest values for numerical and experimental temperatures ( $740{ }^{\circ} \mathrm{C}$ and $732{ }^{\circ} \mathrm{C}$, respectively), the region near the flash land required the lowest number of cycles (293 cycles) for the beginning of thermal fatigue cracks. During the experimental work, plastic strain and mechanical fatigue cracks were observed in this region in addition to thermal cracks.

- The numerical subroutine accurately determined the number of cycles for the onset of thermal fatigue cracks and therefore it can be considered a promising alternative for modeling and simulation of hot forging using closed dies with more complex geometries.

\section{Acknowledgments}

The authors would like to thank Forjas Mocam Ind. Com. Ltda (Contagem, Brazil) for the provision of the facilities used in the experimental work and QX2Box and Quantor (Moscow, Russia) for providing the FEM software license.

\section{References}

1. Brasil. Ministério de Minas e Energias. Anuário Estatístico do Setor Metalúrgico-AESM. 2018 [cited 2018 Sept 9]. Available from: http://http://www.mme.gov.br/documents/1138775/1732813/ ANU\%C3\%81RIO+METAL\%C3\%9ARGICO+2017_12.03.2018. pdf/4c1be82b-88d6-498a-aad8-671048438e20

2. Market Research Future. Metal Forging Market Size Expected to Grow at a CAGR over 6.6\% from 2019 to 2025 [cited 2020 Apr 8]. Available from: https://www.marketresearchfuture. com/press-release/metal-forging-market

3. Buchmayr B. 2016. Damage, lifetime, and repair of forging dies. BHM, 2017;162:88-93. http://dx.doi.org/10.1007/s00501016-0566-3.

4. König W, Klocke F. Fertigungsverfahren. Bd.4. Massivumformung. Dusseldorf: VDI-Verlag; 2006.

5. Lange K, Cser L, Geiger M, Kals JAC. Tool life and tool quality in bulk forming. CIRP Ann. 1992;41(2):667-75.

6. Becker WT, Shipley RJ. Failure analysis and prevention. Vol. 11. Materials Park: ASM International; 2002.

7. Manson SS. Thermal stress and low cycle fatigue. New York: McGraw-Hill; 1996. p. 246-254.

8. Srivastava A, Joshi V, Shivpuri R. Computer modeling and prediction of thermal fatigue cracking in die-casting tooling. Wear. 2004;256:436-42.

9. Magalhães FC, Figueiredo RB, Aguilar MTP, Pertence AEM, Campos HB, Cetlin PR. Susceptibilidade à fadiga térmica de matrizes fechadas para forjamento a quente. Tecnol Metal Mater Min. 2014;11(2):131-7.

10. Grünning K. 1996. Técnica da conformação. São Paulo: Polígono SA.

11. Siegert R, Malek R, Neher R. Forging process, isothermal forging, TALAT-Training in Aluminum Application Technologies Lecture 3402. Stuttgart, Germany: Institut für Umformtechnik, Universität Stuttgart; 1994.

12. Virtanen E, Van Tyne CJ, Levy BS, Brada G. The tempering parameter for evaluating softening of hot and warm forging die steels. J Mater Process Technol. 2013;213:1364-9.

13. Semiatin SL. Metalworking: bulk forming. ASM Handbook. Vol. 14A. Materials Park: ASM International; 2005.

14. Chun L. Modeling of water and lubricant sprays in hot metal working [dissertation]. Ohio: Ohio State University; 2007.

15. Maim S, Norstrom LA. Material-related model for thermal fatigue applied to tool steels in hot-work applications. Met Sci. 1979;13(9):544-50.

16. Sjöström J, Bergström J. Thermal fatigue in hot-working tools. Scand J Metall. 2005;34:221-31. 